\title{
Preparation of Novel Functional Drug Particles Embedded in a Gelling-Swelling Layer (PEGS) for Taste Masking and Subsequent Rapid Drug Release
}

\author{
Shin Ijitsu, ${ }^{a}$ Yohei Hoashi, ${ }^{a}$ Koji Hori,${ }^{a}$ Kazuto Okimoto,${ }^{a}$ Toshiya Kai,${ }^{a}$ Miyako Yoshida, ${ }^{b}$ and \\ Takahiro Uchida*,b \\ ${ }^{a}$ Pharmaceutical Research Laboratories, Pharmaceutical Department, Nipro Corporation; 3023 Nojicho, Kusatsu, \\ Shiga 525-0055, Japan: and ${ }^{b}$ School of Pharmaceutical Sciences, Mukogawa Woman's University; 11-68 Koshien \\ 9-Bancho, Nishinomiya, Hyogo 663-8179, Japan. \\ Received November 24, 2020; accepted January 17, 2021; advance publication released online January 29, 2021
}

The purpose of this research was to develop novel functional drug particles embedded in a gellingswelling layer (PEGS) which are capable of achieving both taste-masking of unpalatable drugs and rapid drug elution. The functional particles had a three-layer structure consisting of a core drug layer, a gellingswelling layer and an outer water-penetration control layer containing a water-insoluble polymer. The concept of formulation design was as follows: when water reaches the gelling-swelling layer, pulverized fine gelling-swelling particles gellate and swell from water absorption to form a rigid layer, thereby preventing drug release. After a defined lag time, the increased volume of the gelling-swelling layer breaks down the outer water-penetration control layer, leading to rapid drug release. In order to adapt this system for use in orally disintegrating tablets, PEGS were prepared at a size of about $250 \mu \mathrm{m}$ using a fine particle-coating method. Ambroxol hydrochloride was used as a model drug for bitterness and the effects of different gellingswelling agents and water-insoluble polymers on drug release characteristics from PEGS were examined. In in vitro dissolution tests, it was shown that the drug dissolution rate from PEGS could be suppressed to about $5 \%$ after $2 \mathrm{~min}$ and increased to more than $85 \%$ after $30 \mathrm{~min}$ by adjusting the composition and thickness of the outer layer. The PEGS expanded about 1.5 -fold and the outer layer was ruptured after 5 min in water.

Key words functional particle; taste masking; coating; gelling-swelling particle

\section{Introduction}

Generally speaking, granules and powders are more easily taken by pediatric and geriatric patients with poor swallowability, than conventional solid oral dosage forms such as tablets and capsules. In recent decades, many formulations have been developed with special advantages aimed at improving drug acceptability and compliance..$^{1-4)}$ Orally disintegrating tablets (ODTs) came onto the Japanese market nearly 25 years ago and their clinical usage is still increasing. This is mainly because of their advantages for patients with poor swallowability and because they do not need to be taken with water. ${ }^{5,6}$ However, if ODTs containing bitter medicines are kept in the mouth with even a small volume of saliva for few seconds, the concentration of dissolved drug in the oral cavity may exceed the bitterness threshold of the medicine. ${ }^{7,8)}$

Recently, ODTs have been developed containing small functional particles with novel taste-masking properties or photostability. ${ }^{9-14)}$ Functional particles for taste masking need to be less than $350 \mu \mathrm{m}$ in diameter from the standpoint of texture and to avoid destruction in the mouth from chewing. ${ }^{15)}$ However, these small particles offer a large specific surface area, such that they easily absorb water which could result in a rapid increase of drug concentrations in saliva, which would make them less palatable and thus decrease adherence. To overcome this barrier, bitterness suppression for 1-2 min while the ODT is in the oral cavity or oesophagus, is required. ${ }^{16-18)}$ However, when the ODT arrives in the upper gastrointestinal tract, the drug must be released smoothly within the absorption range, as a restricted release rate would decrease bioavailability. ${ }^{19,20)}$
For complete drug release from preparations like pellets coated with a water-insoluble polymer, the general membranecontrolled method, whereby a water-soluble polymer is added to the water-insoluble layer as a pore former, is well established. ${ }^{21,22)}$ The drug-release rate is controllable for a long time in the gastrointestinal tract using this method, but it cannot be controlled for the short time it spends in the oral cavity. ${ }^{23)}$

Against this background, a new process has been developed based on the general membrane-controlled release method. This new process can be summarized as follows: particles are prepared which consist of three layers, an inner drug layer, a gelling-swelling layer and an outer water-penetration control layer. After entering the oral cavity, water penetrates the particles through the outer layer. When water reaches the gelling-swelling layer, the volume of this layer expands by gellation and swelling. This expanded layer temporarily prevents water penetration to the next (drug) layer, creating a lag time before drug is released. Once the gelling-swelling layer has been dissolved, drug release is expected to be quite rapid. It is proposed to utilize this new taste-masking method in the development of ODTs.

In this study, the optimal composition of functional drug Particles Embedded in a Gelling-Swelling layer (PEGS) was investigated. The differential effects of various gellingswelling agents and water-insoluble polymers on drug-release characteristics were examined.

\section{Experimental}

Materials Ambroxol hydrochloride (Dong Wha Pharm 
Co., Ltd., Korea) was used as a model drug for bitterness. ${ }^{23)}$ The following materials were screened in this study as watersoluble gelling-swelling agents: carboxymethylcellulose sodium (CMC-Na; Cellogen ${ }^{\circledR}$ grade F-5A, PR-S and F-SC, DKS Co., Ltd., Japan), xanthan gum (Keltrol ${ }^{\circledR}$ grade CG, Sansho Co., Ltd., Japan), hydroxypropylmethylcellulose (HPMC; TC- $5^{\circledR}$ grade E, Shin-Etsu Chemical Co., Ltd., Japan) and polyvinylpyrrolidone (PVP; Kollidon ${ }^{\circledR}$ grade 30, BASF Japan Ltd., Japan).

In the spray-coating process, microcrystalline cellulose spheres (Celphere ${ }^{\circledR}$ grade CP-102, Asahi Kasei Corp., Japan), PVP and hydroxypropylcellulose (HPC; Nisso HPC ${ }^{\circledR}$ grade L, Nippon Soda Co., Ltd., Japan) were used as the core particles, to bind the drug and as a binder for the gelling-swelling agents, respectively.

Ethylcellulose (EC; Ethocel ${ }^{\circledR}$ grade STD 7, DuPont de Nemours, Inc., U.S.A.) and HPMC were used to form the outer water-penetration control layer.

Measurement of Swelling Ratio of Gelling-Swelling Agents Water was gradually added to $100 \mathrm{~g}$ of a gellingswelling agent until the viscosity reached $2000 \mathrm{mPa} \cdot \mathrm{s}$ at $30{ }^{\circ} \mathrm{C}$, measured using a Brookfield-type viscometer (DV1M, Ametek Inc., U.S.A.). The volume of the gel obtained was measured using a measuring cylinder to calculate the swelling ratio, as follows:

$$
(\text { Swelling ratio })=\frac{(\text { Volume of } 2000 \mathrm{mPa} \cdot \mathrm{s} \text { solution })}{(\text { Volume of } 100 \mathrm{~g} \text { gelling-swelling agent })}
$$

Pulverization of Gelling-Swelling Agents The gellingswelling agents were pulverized using the high speed rotor mill (Ultra Centrifugal Mill ZM 200, Verder Scientific Co., Ltd., Germany), the hammer mill (Sample Mill KII-1, Dalton Corp., Japan), the spiral jet mill (200AS, Hosokawa Micron Corp., Japan), or the fluidized bed opposed jet mill (200/1 AFG, Hosokawa Micron Corp.) under the conditions shown in Table 1. Particle size was measured using the laser-scattering

Table 1. Conditions for Pulverization of Gelling-Swelling Agents

\begin{tabular}{llc}
\hline \hline Machines & \multicolumn{1}{c}{ Conditions } \\
\hline High speed rotor mill & Type of rotor & 24-tooth rotor \\
& Sieve size $(\mathrm{mm})$ & 0.08 \\
& Rotary speed $(\mathrm{rpm})$ & 16000 \\
\hline Hammer mill & Sieve size $(\mathrm{mm})$ & 0.5 \\
& Rotary speed $(\mathrm{rpm})$ & 12000 \\
\hline Spiral jet mill & Air pressure $(\mathrm{MPa})$ & 0.6 \\
& Air flow rate $\left(\mathrm{Nm}^{3} / \mathrm{min}\right)$ & 1.7 \\
\hline Fluidized bed & Air pressure $(\mathrm{MPa})$ & 0.6 \\
opposed jet mill & Air flow rate $\left(\mathrm{Nm}^{3} / \mathrm{min}\right)$ & 4.8 \\
\hline
\end{tabular}

Table 2. Preparative Conditions during Spray Coating of the Drug Layer in a Tumbling Fluidized Bed Granulating-Coating Machine

\begin{tabular}{lc}
\hline \hline Batch size $(\mathrm{g})$ & 200 \\
Inlet air temp. $\left({ }^{\circ} \mathrm{C}\right)$ & 70 \\
Outlet air temp. $\left({ }^{\circ} \mathrm{C}\right)$ & $35-38$ \\
Fluidizing air flow rate $\left(\mathrm{m}^{3} / \mathrm{min}\right)$ & 0.40 \\
Spray rate $(\mathrm{g} / \mathrm{min})$ & $2-4$ \\
Spray air pressure $(\mathrm{MPa})$ & 0.50 \\
\hline
\end{tabular}

particle size distribution analyzer (LA-950, Horiba, Ltd., Japan)

Drug-Coated Core Particles A drug suspension was prepared in $2.5 \%(\mathrm{w} / \mathrm{v})$ PVP aqueous solution. Microcrystalline cellulose spheres (CP-102) were placed in a tumbling fluidized bed granulating-coating machine (MP-01, Powrex Corp., Japan) and the coating solution was sprayed under the conditions shown in Table 2. After drying, the drug-coated particles were sieved through a $355-\mu \mathrm{m}$ sieve to prevent aggregation (formulation shown in Table 3).

Application of Gelling-Swelling Layer and Outer Layer Coating Pulverized fine gelling-swelling agents were suspended in $1 \%(\mathrm{w} / \mathrm{v}) \mathrm{HPC}$ ethanol solution. Drug-coated particles were put into a tumbling fluidized bed granulatingcoating machine (MP-01, Powrex Corp., Japan) and the suspension was coated by spraying. After drying, the particles were sieved through a $355-\mu \mathrm{m}$ sieve to prevent aggregation.

These particles were then coated with an outer layer containing a water-insoluble polymer by spraying with a $5 \%(\mathrm{w} / \mathrm{v})$ polymer solution, prepared by dissolving EC and HPMC in a water-ethanol mixture $(1: 9, \mathrm{w} / \mathrm{w})$. The operating conditions for spray coating are shown in Table 4.

Table 5 shows the results obtained from experiments using different formulations to determine (a) the effect of different gelling-swelling agents on drug release from particles without a water-penetration control layer (F1-3), (b) the effect of the amount of gelling-swelling agent used on drug release from PEGS (F4-6), (c) the effect of varying the composition and thickness of the outer layer on drug release from PEGS (F6-8), and (d) the effect of using gelling-swelling agents with different swelling ratios on drug release from PEGS (F8-11).

Microscopic Appearance of Particles The functional PEGS were viewed using a scanning electron microscope (TM3030 Plus, Hitachi High-Tech Corp., Japan) and energy dispersive X-ray spectroscopy (Quantax 70, Bruker nano $\mathrm{GmbH}$, Germany). The swelling of functional particles in water was confirmed using a digital microscope (VHX-6000, Keyence Corp., Japan).

Drug-Release Study The drug-release profiles of the various particles were investigated using the Japanese Phar-

Table 3. Formulation of Drug-Coated Particles

\begin{tabular}{lcc}
\hline \hline Function & Component & Weight ratio $(\mathrm{w} / \mathrm{w})$ \\
\hline Core particle & CP-102 & 100 \\
Drug & Ambroxol hydrochloride & 10 \\
Binder & PVP & 2.5 \\
\hline
\end{tabular}

Table 4. Preparative Conditions during Spray Coating in a Tumbling Fluidized Bed Granulating-Coating Machine

\begin{tabular}{lcc}
\hline \hline & $\begin{array}{c}\text { Gelling-swelling } \\
\text { layer }\end{array}$ & Outer layer \\
\hline Batch size $(\mathrm{g})$ & 200 & 200 \\
Inlet air temp. $\left({ }^{\circ} \mathrm{C}\right)$ & 50 & 50 \\
Outlet air temp. $\left({ }^{\circ} \mathrm{C}\right)$ & $30-35$ & $30-35$ \\
Fluidizing air flow rate $\left(\mathrm{m}^{3} / \mathrm{min}\right)$ & 0.40 & 0.40 \\
Spray rate $(\mathrm{g} / \mathrm{min})$ & $1-3$ & $1-2$ \\
Spray air pressure $(\mathrm{MPa})$ & 0.50 & 0.50 \\
\hline
\end{tabular}


Table 5. Formulations of Functional Particles Used in the Experiments on Drug Release

(a) Experiments on varying the amount of gelling-swelling agent on drug release from particles without a water-penetration control layer (F1-3)

\begin{tabular}{|c|c|c|c|c|c|}
\hline Layer & Function & Component & $\mathrm{F} 1$ & $\mathrm{~F} 2$ & F3 \\
\hline \multirow[t]{2}{*}{ Gelling-swelling layer } & Gelling-swelling agent & CMC-Na PR-S & - & 20 & 30 \\
\hline & Binder & HPC & - & 5 & 7.5 \\
\hline
\end{tabular}

(b) Experiments on varying the amount of gelling-swelling agent on drug release from PEGS (F4-6)

\begin{tabular}{llcccc}
\hline \multirow{2}{*}{ Layer } & \multicolumn{1}{c}{ Function } & Component & F4 & F5 & F6 \\
\hline \multirow{2}{*}{ Gelling-swelling layer } & Gelling-swelling agent & CMC-Na PR-S & - & 20 & 30 \\
& Binder & HPC & 7.5 & 5 & 7.5 \\
\cline { 1 - 3 } & Water-insoluble polymer & EC & 8.6 & 10 & 11 \\
& Pore former & HPMC & 2.15 & 2.5 & 2.75 \\
\hline
\end{tabular}

(c) Experiments on varying the composition and thickness of the outer later on drug release from PEGS (F6-8)

\begin{tabular}{|c|c|c|c|c|c|}
\hline Layer & Function & Component & F6 & F7 & F8 \\
\hline \multirow[t]{2}{*}{ Gelling-swelling layer } & Gelling-swelling agent & CMC-Na PR-S & 30 & 30 & 30 \\
\hline & Binder & $\mathrm{HPC}$ & 7.5 & 7.5 & 7.5 \\
\hline \multirow[t]{2}{*}{ Outer layer } & Water-insoluble polymer & $\mathrm{EC}$ & 11 & 22 & 24.75 \\
\hline & Pore former & HPMC & 2.75 & 5.5 & 2.75 \\
\hline
\end{tabular}

(d) Experiments on varying the swelling ratio of gelling-swelling agent on drug release from PEGS (F8-11)

\begin{tabular}{|c|c|c|c|c|c|c|}
\hline Layer & Function & Component & F8 & F9 & F10 & F11 \\
\hline \multirow[t]{4}{*}{ Gelling-swelling layer } & Gelling-swelling agent & CMC-Na PR-S & 30 & - & - & - \\
\hline & & CMC-Na F-5A & - & 30 & - & - \\
\hline & & CMC-Na F-SC & - & - & 30 & 30 \\
\hline & Binder & HPC & 7.5 & 7.5 & 7.5 & 7.5 \\
\hline \multirow[t]{2}{*}{ Outer layer } & Water-insoluble polymer & EC & 24.75 & 24.75 & 24.75 & 49.5 \\
\hline & Pore former & HPMC & 2.75 & 2.75 & 2.75 & 5.5 \\
\hline
\end{tabular}

Each Component is represented as a weight ratio $(\mathrm{w} / \mathrm{w})$ and all drug-coated particles were $100 \mathrm{w} / \mathrm{w}$.

Table 6. Swelling Ratio of Swelling Agents Screened

\begin{tabular}{lcc}
\hline \hline Gelling-swelling agent & & Swelling ratio \\
\hline PVP & & 1.4 \\
HPMC & & 4.0 \\
CMC-Na & F-5A & 6.7 \\
& PR-S & 12.8 \\
& F-SC & 26.3 \\
Xanthan gum & & 69.3 \\
\hline
\end{tabular}

macopoeia (JP) 17 paddle method at a rotation speed of $50 \mathrm{rpm}$, using $900 \mathrm{~mL}$ of JP 2nd test solution ( $\mathrm{pH}$ 6.8) or JP 1st test solution ( $\mathrm{pH} 1.2)$ maintained at $37 \pm 0.5^{\circ} \mathrm{C}$. A $20-\mathrm{mL}$ aliquot of the eluate was taken at the times specified and the volume of study solution immediately restored with fresh test solution, preheated to $37^{\circ} \mathrm{C}$. After filtration (Millex ${ }^{\circledR}$ syringe filters, $0.45 \mu \mathrm{m}$, type polytetrafluoroethylene, Merck KGaA, Germany), the amount of released drug was measured by HPLC (Prominence, Shimadzu Corp., Japan) at a wavelength of $220 \mathrm{~nm}$. The quantity of particles used in each test was designed to be sufficient to contain $15 \mathrm{mg}$ Ambroxol hydrochloride, based on normal drug dosage.

\section{Results and Discussion}

Selection of Gelling-Swelling Agents The swelling ratios of several gelling-swelling agents were evaluated and the results are summarized in Table 6.
The critical properties of the gelling-swelling agent for this formulation concept is that it swells enough to rupture the outer layer after it has absorbed water and gellated and the time it takes for this to occur. A gelling-swelling agent with too high a swelling ratio, such as xanthan gum, may cause the particles to stick to the oral cavity due to premature elution of gel, causing discomfort and, in some cases, unintentional drug release. In fact, when attempts were made to prepare a prototype PEGS using xanthan gum, even the small amount of dissolved xanthan gum showed such high adhesion to the manufacturing equipment that production was impossible.

In our study, commercially available $\mathrm{CMC}-\mathrm{Na}$, (which has relatively high swelling ratios with a wide range of about 7-25 for products graded by viscosity and degree of etherification), was selected as the gelling-swelling agent to be used in further experiments (see below).

Particle Size Control of Gelling-Swelling Agent PEGS were prepared using a fine particle-coating method. It was not practical to dissolve the gelling-swelling agent in water because the spray solution became very viscous and needed to be diluted with such large volumes. An attempt was made to disperse the gelling-swelling agent in ethanol before spraying, but the particle size of commercially available CMC-Na (diameter about $90 \mu \mathrm{m}$ ) was too large for it to form a layer on the drug-coated particles and therefore it first needed to be pulverized. In addition to enabling the formation of a uniform layer, the pulverization of the gelling-swelling agent permits its rapid dissolution once the outer layer has been broken 
Table 7. Particle Size of CMC-Na (PR-S) before and after Pulverization

\begin{tabular}{lccc}
\hline \hline \multirow{2}{*}{ Sample } & \multicolumn{3}{c}{ Size $(\mu \mathrm{m})$} \\
\cline { 2 - 4 } & $d 10^{* *}$ & $d 50^{*}$ & $d 90^{* * *}$ \\
\hline Before processing & 31.6 & 88.2 & 194.3 \\
Rotor milled & 15.4 & 33.7 & 68.7 \\
Hammer milled & 28.8 & 56.3 & 110.2 \\
Spiral jet milled & 8.1 & 15.6 & 33.2 \\
Fluidized bed opposed jet milled & 1.0 & 4.7 & 8.2 \\
\hline \multirow{2}{*}{$* d 50=$ particle diameter at a cumulative value of $50 \%$ in a particle size distribu- } \\
tion (in terms of volume) by a laser diffraction scattering method; $* * d 10=$ particle \\
diameter at a cumulative value of $10 \%$ in a particle size distribution (in terms of \\
volume) by a laser diffraction scattering method; $* * * d 90=$ particle diameter at a \\
cumulative value of $90 \%$ in a particle size distribution (in terms of volume) by a laser \\
diffraction scattering method.
\end{tabular}

through, such that drug release from the inner layer is then rapid. Pulverization thus permits a smaller particle size of PEGS, suitable for use in ODTs, and improves the swelling power due to the increased specific surface area. However, pulverizing CMC-Na with a rotor mill, a hammer mill, or a spiral jet mill proved difficult. Finally, it was found to be possible to pulverize the $\mathrm{CMC}-\mathrm{Na}$ in a fluidized bed opposed jet mill, which uses the collision of opposing compressed air streams to collide and crush the materials. ${ }^{24,25)}$ These results show that, when soft fibrous substances such as CMC-Na are to be finely pulverized, it is important to select a method that can apply an inescapable force, pressure and shearing forces not being easily applied using dry mechanical crushing methods. Table 7 shows the particle size of CMC-Na (PR-S) before and after pulverization.

It was shown that a gelling-swelling layer coating can be created with CMC-Na pulverized to about $5 \mu \mathrm{m}$. Coating was unsuccessful when a larger particle size was used, which suggests that guest particles need to be pulverized to $1 / 40$ th of the size of host particles in spray coating.

Effect of Gelling-Swelling Agent on Drug-Release Profile To investigate the effect of the gelling-swelling layer on the drug-release profile, PEGS containing different thicknesses of gelling-swelling layer were prepared and subjected to dissolution tests. In general, when ODTs are taken without drinking water, most of the drug particles in the formulation are conveyed from the oral cavity to the stomach within $1 \mathrm{~min} .{ }^{16-18)}$ The goal of taste masking was therefore to suppress the drug dissolution rate to $10 \%$ or less at 2 min after the start of the dissolution test. In order to simulate the environment of the oral cavity, tests were conducted at $\mathrm{pH} 6.8$, close to the $\mathrm{pH}$ in the oral cavity.

Although drug elution will depend on the specific solubility and dissolution rate of the drug used, drug elution of more than $80 \%$ at $30 \mathrm{~min}$ was used to represent a successful drugrelease profile.

Figure 1 shows in vitro drug-release profiles of ambroxol from particles prepared without a water-penetration control (outer) layer. The coating of the gelling-swelling agent slightly reduced the dissolution rate at 2 min but had little effect on the drug-release profile. This indicates that the layer of pulverized gelling-swelling agent dissolves in water rapidly enough not to delay drug release, and that an outer layer is required to suppress drug elution.

When the drug-release profiles of PEGS with different thicknesses of gelling-swelling layer were coated with the same

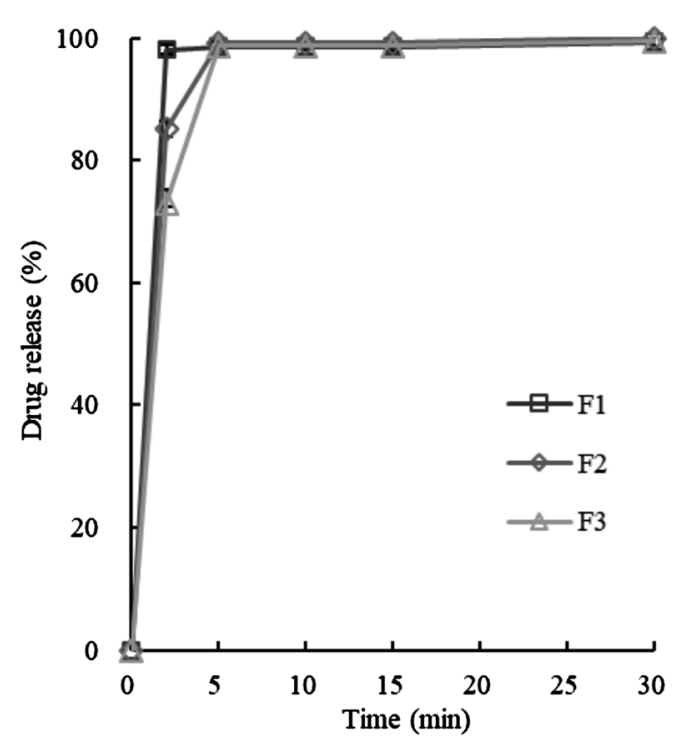

Fig. 1. Effect of the Gelling-Swelling Agent on the Drug-Release Profile from Particles without an Outer Layer

The JP paddle method was used at a rotation speed of $50 \mathrm{rpm}$, using $900 \mathrm{~mL}$ of JP 2 nd test solution ( $\mathrm{pH} 6.8)$ at $37 \pm 0.5^{\circ} \mathrm{C}$. For details of the formulation composition, see Table 5(a). Data are expressed as mean \pm standard deviation (S.D.) $(n=6)$.

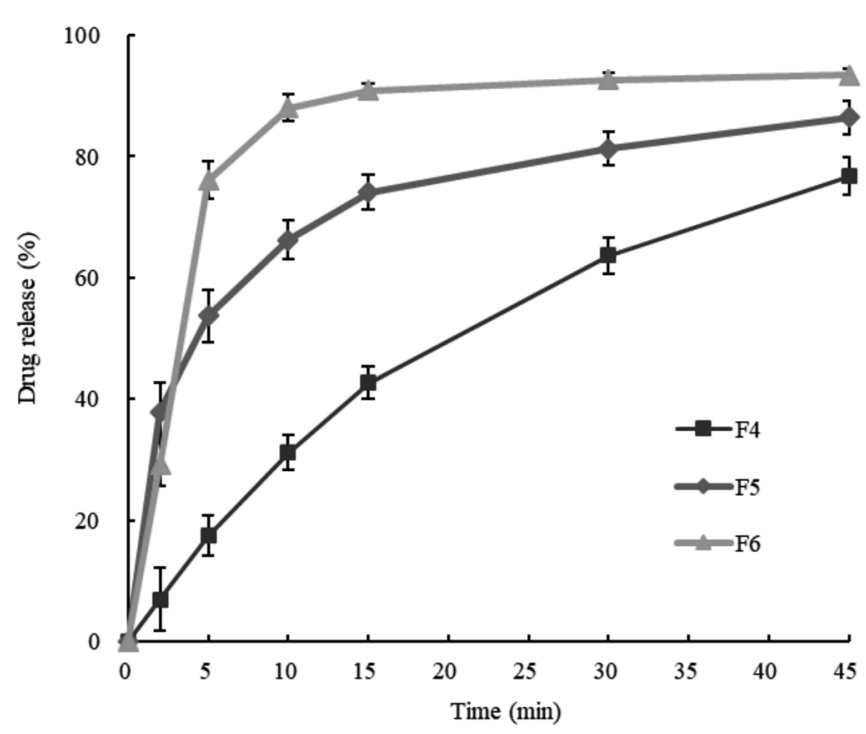

Fig. 2. Effect of Varying the Amount of Gelling-Swelling Agent on Drug-Release Profile

The JP paddle method was used at a rotation speed of $50 \mathrm{rpm}$, using $900 \mathrm{~mL}$ of JP 2nd test solution $(\mathrm{pH} 6.8)$ at $37 \pm 0.5^{\circ} \mathrm{C}$. For details of formulation composition, see Table 5(b). Data are expressed as mean \pm S.D. $(n=6)$

composition and proportion of outer layer, it was confirmed that the thickness of the gelling-swelling layer affects the destruction of the outer layer (Fig. 2). PEGS containing 30\% (w/w) of gelling-swelling agent relative to the core particle showed a rapid drug-release profile (F6), despite the addition of a water-insoluble layer. On the other hand, the dissolution of F4, which contained no gelling-swelling agent, was less than $80 \%$, even at $45 \mathrm{~min}$. PEGS containing $20 \%$ (w/w) of gellingswelling agent (F5) showed a drug-release profile between that of F4 and F6. Although the initial drug release of F5 was improved compared to $\mathrm{F} 4$, the subsequent release rate was decreased, suggesting that the swelling of the gelling-swelling layer is not adequate to completely rupture the outer layer. 


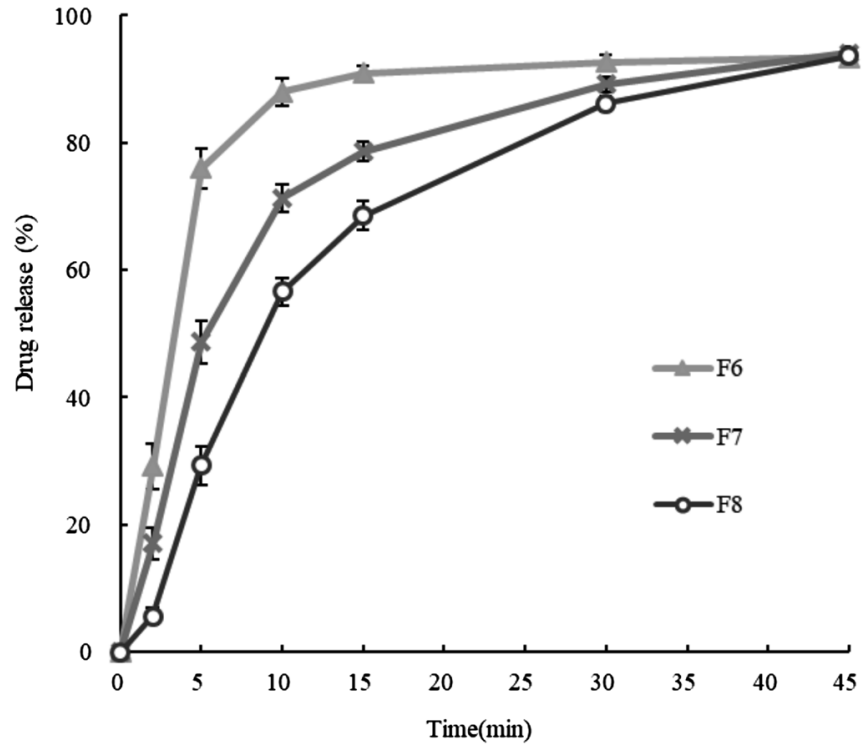

Fig. 3. Effect of Composition and Thickness of Outer Layer on DrugRelease Profile

The JP paddle method was used at a rotation speed of $50 \mathrm{rpm}$, using $900 \mathrm{~mL}$ of JP 2nd test solution ( $\mathrm{pH} 6.8)$ at $37 \pm 0.5^{\circ} \mathrm{C}$. For details of formulation composition, see Table 5(c). Data are expressed as mean \pm S.D. $(n=6)$.

This result indicates that a gelling-swelling layer is essential to achieve immediate drug release in the upper gastrointestinal tract from a taste-masked particle coated with a water-insoluble polymer, and that adjusting the amount of gelling-swelling agent may allow different release profiles to be achieved.

Since drug release from PEGS at 2 min was not sufficiently suppressed, experiments were performed to optimize the composition and thickness of the outer layer.

Effect of Composition and Thickness of Outer Layer on Drug-Release Profile The optimal formulation of the outer layer to achieve bitterness suppression in the oral cavity was investigated. Based on the formulation of F6, which did not suppress drug release at the initial stage of dissolution, F7 was coated with a double amount of outer layer. However, suppression of initial drug release was not achieved when the outer layer contained $20 \%$ pore former due to a high rate of water penetration and subsequent rapid swelling of the gelling-swelling layer. By increasing the ratio of the waterinsoluble polymer in the outer layer to $90 \%$, it was possible to reduce the drug-elution rate at $2 \mathrm{~min}$ to about $5 \%$ (Fig. 3, F8). The drug-release rate after a lag time of $30 \mathrm{~min}$ was not significantly affected, showing a release profile of over $80 \%$. This suggests that the degree of bitterness suppression can be controlled by adjusting the thickness of the outer layer, which alters the water-penetration rate. Swelling of the gellingswelling layer ruptures the outer layer after a predetermined lag time, resulting in rapid drug release.

Swallowed particles will be exposed to a low $\mathrm{pH}$ environment in the stomach. As shown in Fig. 4, PEGS is able to achieve rapid drug release at a $\mathrm{pH}$ of 1.2 , which mimics the conditions of the upper gastrointestinal tract.

It is therefore considered that the developed PEGS can achieve both suppression of drug release in the oral cavity and subsequent rapid drug release in the upper gastrointestinal tract, thus allowing sufficient bioavailability.

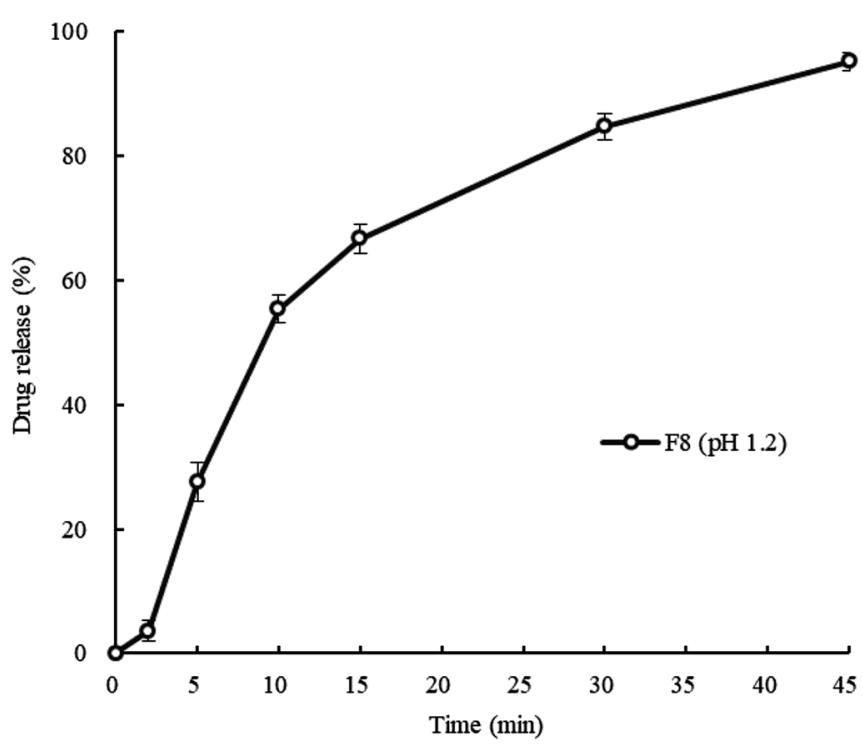

Fig. 4. Effect of Low pH (1.2) on the Drug-Release Profile of Formulation F8

The JP paddle method was used at a rotation speed of $50 \mathrm{rpm}$, using $900 \mathrm{~mL}$ of JP 1st test solution ( $\mathrm{pH}$ 1.2) maintained at $37 \pm 0.5^{\circ} \mathrm{C}$. For details of formulation composition, see Table 5(d). Data are expressed as mean \pm S.D. $(n=6)$.

Observation of Structure and Swelling of PEGS Scanning electron micrographs of particles coated with each layer and the result of analyzing a cross-section of PEGS by energy dispersive X-ray spectroscopy are shown in Figs. 5 and 6, respectively. Spherical PEGS with three-layer structures were prepared. Each layer was formed concentrically with uniform thickness, with the drug layer contained inside the gellingswelling layer. If the surface of the particle coated gellingswelling layer becomes rough and uneven, the outer layer cannot be uniformly coated, and the desired release control cannot be achieved. Using pulverized fine gelling-swelling agents, particles with a smooth surface are prepared and it was achieved that each layer was formed homogeneously. The particle size of the final coated particles was about $250 \mu \mathrm{m}$, which is a suitable size for use in ODTs.

Under a digital microscope, the particle size could be seen to expand about 1.5 -fold in water, while the outer layer, containing the water-insoluble polymer, was ruptured in PEGS left for $5 \mathrm{~min}$ in water (Fig. 7). This result indicates that the desired particle design had been achieved. The time required for the outer layer to be destroyed by the swelling of the gelling-swelling layer allows taste masking to be achieved in the oral cavity.

Effect of Swelling Ratio of the Gelling-Swelling Agent on Drug-Release Profile To investigate the versatility and potential of this technology, PEGS using gelling-swelling agents with relatively high or low swelling ratios were prepared and tested, based on formulation F8. In the dissolution test shown in Fig. 8, PEGS containing an agent with a relatively low swelling ratio could not completely rupture the outer layer and thus showed a slow drug-release profile. Although increasing the quantity of the gelling-swelling layer might achieve complete rupture, this would result in an unacceptable increase in particle size. On the other hand, although PEGS containing an agent with a higher swelling ratio showed a fast drug-release profile, the dissolution rate at $2 \mathrm{~min}$ was not sufficiently suppressed, meaning that the outer layer would be 


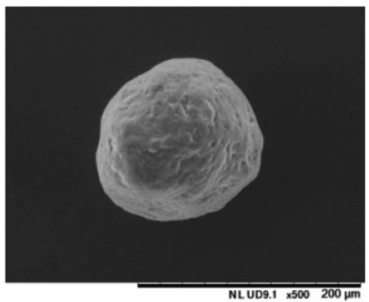

(a)

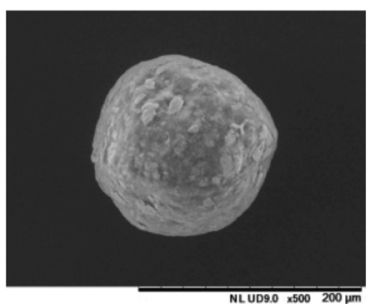

(b)

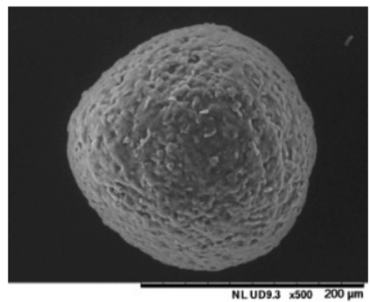

(c)

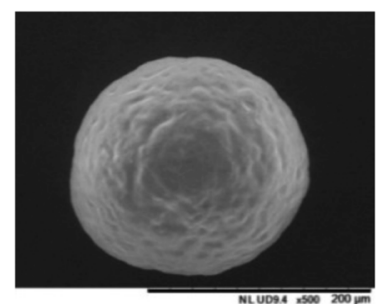

(d)

Fig. 5. Scanning Electron Micrographs of Each Layer of PEGS (F8)

(a) Core particle; (b) drug-layer-coated particle; (c) gelling-swelling-layer-coated particle; (d) final outer-layer-coated particle. Mean diameter of final particle (F8) is about $250 \mu \mathrm{m}$.

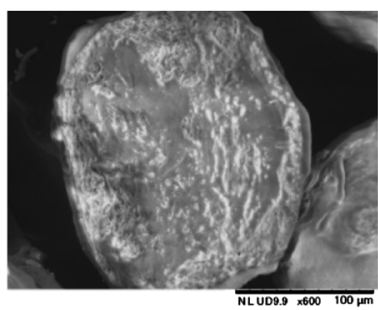

(a)

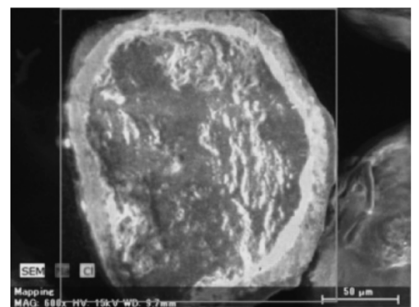

(b)

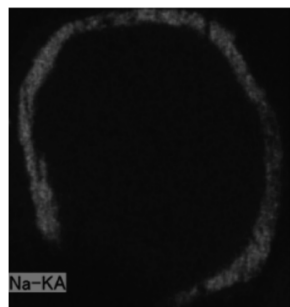

(c)

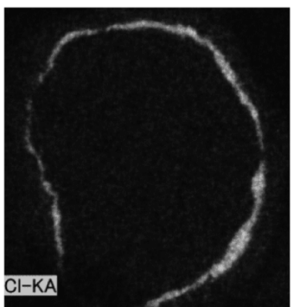

(d)

Fig. 6. Observation of a Cross-Section of PEGS (F8)

(a) Scanning electron micrograph of a cross-section; (b) energy dispersive X-ray spectroscopy of a cross-section; gray area: Na element, light gray area: Cl element; (c) $\mathrm{Na}$ element mapping indicating the distribution of CMC-Na (gelling-swelling layer, mean thickness about $20 \mu \mathrm{m}$ ); (d) Cl element mapping indicating the distribution of ambroxol hydrochloride (drug layer, mean thickness about $5 \mu \mathrm{m}$ ).

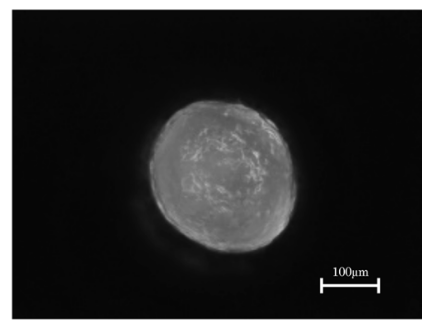

(a)

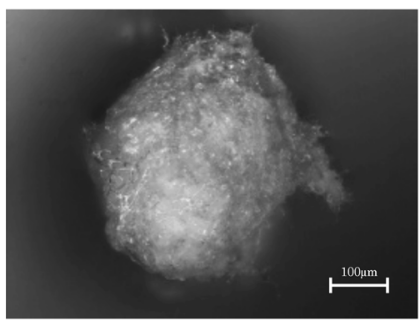

(b)

Fig. 7. Micrographs Showing PEGS before and after Swelling in Water

(a) Before swelling; (b) after $5 \mathrm{~min}$. The mean diameter of the swollen particle is about $380 \mu \mathrm{m}$.

too easily ruptured by the relatively strong swelling force of the gelling-swelling layer. An increase in the thickness of the water-insoluble layer would therefore be necessary to suppress initial drug release. This suggests that the target profile could be achieved with a thinner gelling-swelling layer if an agent with a relatively high swelling ratio were used. Based on these results, the use of a gelling-swelling agent with a swelling ratio of 10 or more is recommended to achieve taste masking.

Interestingly, it was found that the lag time was extended to $5 \mathrm{~min}$ in F11 in which the thickness of the outer waterinsoluble layer had been increased relative to F10 with the intention of reducing drug dissolution at $2 \mathrm{~min}$. The drug was released rapidly after the lag time, reaching a dissolution rate of over $80 \%$ in $30 \mathrm{~min}$. This suggests that, in addition to reducing the water penetration rate by increasing the amount of outer layer, use of a gelling-swelling agent with a relatively high swelling ratio results in an increase in the impermeability of the gelling-swelling layer which takes longer to dissolve, trapping the drug inside even after the outer layer has broken up. Consequently the lag time, i.e., the time required for disso- lution and diffusion of the gelling-swelling layer, is extended.

This result supports the conclusion that the drug-release lag time can be adjusted by changing the grade or amount of gelling-swelling agent used, and the composition and thickness of the outer layer.

Although the swelling ratio of a general disintegrant such as sodium starch glycolate has previously been reported as high, ${ }^{26)}$ when CMC-Na was used as gelling-swelling agent in the present study, it showed a swelling ratio at least 10 -fold higher than the ratio described previously. Owing to the high swellable power and water-soluble properties of CMC-Na, the outer layer of PEGS containing CMC-Na ruptures rapidly on contact with water, leading to rapid drug release after a lag time of only a few minutes, compared with previous reports of methods using a general disintegrant with a delay time of several hours. ${ }^{27)}$

The principle used to produce the PEGS described here seems to be capable of masking unpleasant bitterness in the oral cavity while obtaining rapid dissolution in the upper gastrointestinal tract. Yoshida et al. have also reported on a 
(a)

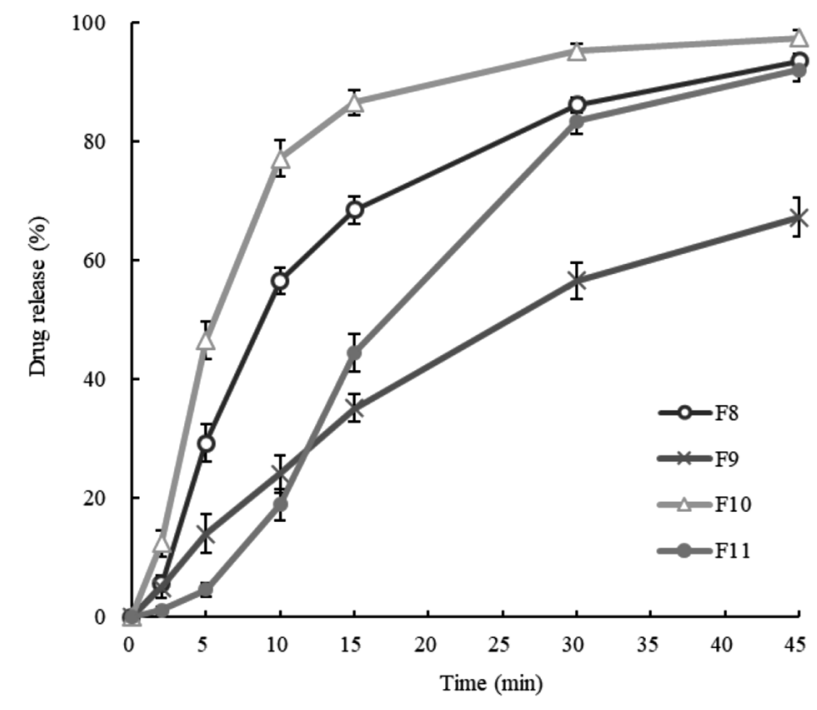

(b)

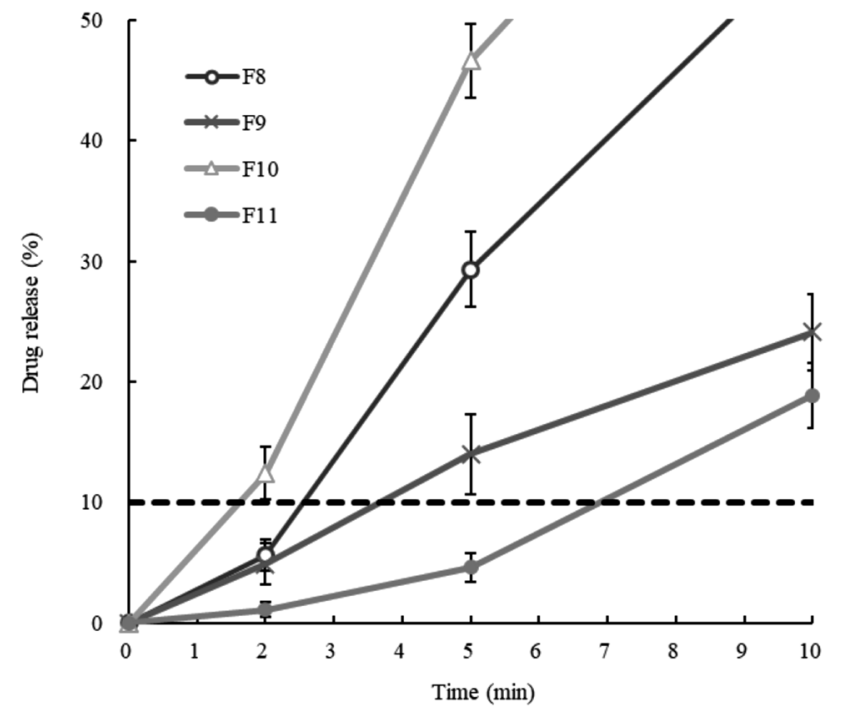

Fig. 8. Effect of the Swelling Ratio of the Gelling-Swelling Agent on Drug-Release Profile

The JP paddle method was used at a rotation speed of $50 \mathrm{rpm}$, using $900 \mathrm{~mL}$ of JP 2 nd test solution ( $\mathrm{pH} 6.8$ ) maintained at $37 \pm 0.5^{\circ} \mathrm{C}$. (a) Drug release over $45 \mathrm{~min}$; (b) enlarged view of drug release during the first $10 \mathrm{~min}$. Data are expressed as mean \pm S.D. $(n=6)$.

controlled drug-release method with a short lag time using a salting-out taste-masking system. ${ }^{12)}$ However, as this technology uses a $\mathrm{pH}$ adjuster such as sodium carbonate, the drug dissolution profile may depend on the ambient $\mathrm{pH}$. The swelling property of $\mathrm{CMC}-\mathrm{Na}$, a neutral substance, was $\mathrm{pH}$ independent, and PEGS containing CMC-Na showed $\mathrm{pH}$-independent drug release.

\section{Conclusion}

A novel PEGS was designed for taste masking at a size suitable for use in ODTs, with the goal of achieving both suppression of drug release in the oral cavity and subsequent rapid drug release in the upper gastrointestinal tract. To obtain efficient coating with the selected gelling-swelling agent CMC-Na, it was necessary to pulverize it to an average diameter of about $5 \mu \mathrm{m}$, which could be achieved using a fluidized bed opposed jet mill. The target drug-release profile in in vitro dissolution tests could be achieved using the prepared PEGS. This technology has the potential to allow the drug-release lag time to be controlled by altering the composition and/or thickness of the gelling-swelling layer and water-penetration control layer. However, if PEGS were to be used in a commercially produced ODT, the compressive pressures applied to the particles during tableting may damage their structure in such a way as to alter the drug-release control function. Therefore, the use of PEGS in ODTs requires further development. In addition, this novel controlled-release method involves the coating of multiple layers on particles of about $200 \mu \mathrm{m}$, which requires the use of precise coating technology applied under appropriate conditions and necessitating lengthy production times. With further development of this coating technology, however, we hope to achieve a method which is both more simple and highly efficient.

Acknowledgments Appreciation is due to Mr. T. Hayashida, Mr. Y. Nakano and Mr. J. Yamazaki for their valuable suggestions in developing this formulation. Acknowledgements also go to Mr. K. Inoue and Mr. A. Aizawa for their assistance in performing assays.

Conflict of Interest This study was designed and funded by Nipro Corporation.

\section{References}

1) Borges A. F., Silva C., Coelho J. F. J., Simōes S., J. Control. Release, 206, 1-19 (2017).

2) Van Riet-Nales D. A., Kozarewicz P., Aylward B., de Vries R., Egberts T. C., Rademaker C. M., Schobben F. A. M., AAPS PharmSciTech, 18, 241-249 (2017).

3) Slavkova M., Breitkreutz J., Eur. J. Pharm. Sci., 75, 2-9 (2015).

4) Preis M., AAPS PharmSciTech, 16, 234-251 (2015).

5) Takahashi T., Therapeutic Research, 27, 1219-1225 (2006).

6) Umaki Y., Nozaki S., Sugishita S., Shiimoto K., Hashiguchi S., Inui T., Adachi K., Clin. Neurol., 49, 90-95 (2009).

7) Uchida T., Yoshida M., Hazekawa M., Haraguchi T., Furuno H., Teraoka M., Ikezaki H., J. Pharm. Pharmacol., 65, 1312-1320 (2013).

8) Tokuyama E., Matsunaga C., Yoshida K., Mifsud J. C., Irie T., Yoshida M., Uchida T., Chem. Pharm. Bull., 57, 382-387 (2009).

9) Mizumoto T., Tamura T., Kawai H., Kajiyama A., Itai S., Chem. Pharm. Bull., 56, 530-535 (2008).

10) Sugiura T., Uchida S., Namiki N., Chem. Pharm. Bull., 60, 315-319 (2012).

11) Yan Y., Woo J. S., Kang J. H., Yong C. S., Choi H., Biol. Pharm. Bull., 33, 1364-1370 (2010).

12) Yoshida T., Tasaki H., Maeda A., Katsuma M., Uchida T., J. Control. Release, 131, 47-53 (2008).

13) Yoshida T., Tasaki H., Maeda A., Katsuma M., Sako K., Uchida T., Chem. Pharm. Bull., 56, 1579-1584 (2008).

14) Shimizu T., Sugaya M., Nakano Y., Izutsu D., Mizukami Y., Okochi K., Tabata T., Hamaguchi N., Igari Y., Chem. Pharm. Bull., 51, 1121-1127 (2003).

15) Shimizu T., Nakano Y., Morimoto S., Tabata T., Hamaguchi N., Igari Y., Chem. Pharm. Bull., 51, 942-947 (2003). 
16) Morita T., Yakugaku Zasshi, 123, 665-671 (2003).

17) Crossner G. C., Hase J. C., Birkhed D., Caries Res., 25, 201-206 (1991).

18) Siqueira L. W., Bermejo R. P., Mustacchi Z., Nicolau J., Clin. Oral Investig., 9, 26-29 (2005).

19) Löbenberg R., Krämer J., Shah P. V., Amidon L. G., Dressman B. J., Pharm. Res., 17, 439-444 (2000).

20) Blume H., Ali L. S., Siewert M., Drug Dev. Ind. Pharm., 19, 2713 2741 (1993).

21) Nanda A., Kanadarapu R., Garg S., Indian J. Pharm. Sci., 64, 10-17 (2002).

22) Sohi H., Sultana Y., Khar K. R., Drug Dev. Ind. Pharm., 30, 429-
448 (2004).

23) Uchida T., Sugino Y., Hazekawa M., Yoshida M., Haraguchi T., Chem. Pharm. Bull., 60, 949-954 (2012).

24) Fukunaka T., Golman B., Shinohara K., Int. J. Pharm., 311, 89-96 (2006).

25) Chan W. L., Lee C. C., Heng W. S. P., Drug Dev. Ind. Pharm., 28, 939-947 (2002).

26) Zhao N., Augsburger L. L., AAPS PharmSciTech, 6, 120-126 (2005).

27) Ueda S., Hata T., Asakura S., Yamaguchi H., Kotani M., Ueda Y., J. Drug Target., 2, 35-44 (1994). 